\title{
Investigating heat and magnetic source depths in the Soutpansberg Basin, South Africa: exploring the Soutpansberg Basin Geothermal Field
}

\author{
P. K. Nyabeze ${ }^{*}$ (D) and O. Gwavava
}

${ }^{*}$ Correspondence: pnyabeze@gmail.com Department of Geology, University of Fort Hare, Private Bag X1314, Alice 5700, South Africa

\begin{abstract}
The research was conducted to seek geothermal energy potential in the Soutpansberg Basin, located in the northern part of South Africa. The depths of the potential heat sources were computed from the radially averaged power spectrum of airborne magnetic data. Shallower magnetic sources were delineated using the Euler deconvolution method. An anticline at depths of $2.0-3.5 \mathrm{~km}$ was delineated in the central part of the basin. Potential magnetic and basement heat sources exist between depths of 4.8 and $11.1 \mathrm{~km}$. Airborne magnetic data sets with larger window sizes are preferred for depth computations, as they preserve spectral signatures of deeper sources and reduce the contribution of shallower sources. The research clearly highlighted evidence for the existence of the Soutpansberg Basin Geothermal Field.
\end{abstract}

Keywords: Soutpanberg Basin, Depth, Geothermal, Heat, Hot spring, Magnetic

\section{Background}

This research was carried out as part of a program for exploring the geothermal potential in South Africa. Airborne magnetic data were filtered to determine magnetic and heat source depth information of the Soutpansberg Basin in South Africa. The Soutpansberg Basin is located in the northeastern part of South Africa and has four recorded hot springs, at Dopeni, Mphephu, Sagole, and Siloam (Fig. 1). In the central part of the basin, the Soutpansberg Formation reaches a maximum thickness of approximately $3.5 \mathrm{~km}$ (Barker et al. 2006). A total thickness of approximately $12 \mathrm{~km}$ was reported for the Soutpansberg Group volcano-sedimentary formations (Bumby et al. 2001). Khoza et al. (2013) described the Soutpansberg Basin as a 40-km-wide, 300-km-long, and 7-kmthick volcano-sedimentary trough. Deep-seated aquifers in faulted volcanic terrains are potential sources of geothermal energy (Banks and Schäffler 2006). The heat source is assumed to be the depth at which crustal rocks lose their ferromagnetic properties, the curie depth (Nwankwo et al. 2009).

The airborne magnetic data, which were analysed in this study, were flown in 1973 along 1000-m-separated south-to-north-oriented lines with a mean ground clearance

(c) 2016 The Author(s). This article is distributed under the terms of the Creative Commons Attribution 4.0 International License (http://creativecommons.org/licenses/by/4.0/), which permits unrestricted use, distribution, and reproduction in any medium, provided you give appropriate credit to the original author(s) and the source, provide a link to the Creative Commons license, and indicate if changes were made. 


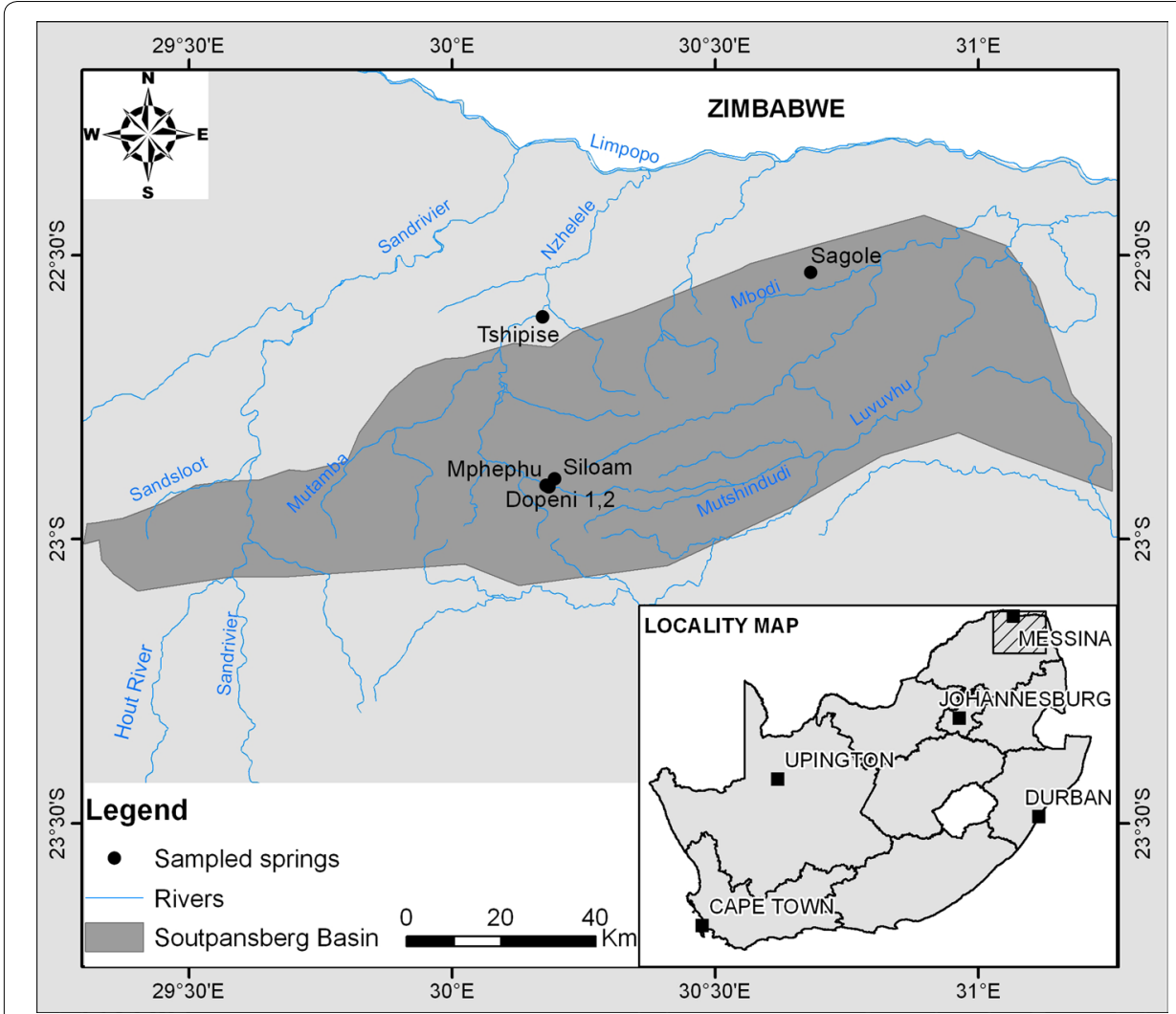

Fig. 1 Location map of the Soutpansberg Basin, showing the Dopeni, Mphephu, Sagole, and Siloam hot springs (Shabalala et al. 2015)

of $150 \mathrm{~m}$ (Ledwaba et al. 2009). The magnetic data were recorded using a Geometrics Model G803 magnetometer with an accuracy of $1.0 \mathrm{nT}$ (Ledwaba et al. 2009). Pilkington et al. (2000) processed magnetic data by elevating the observation datum to reduce the effect of the sediment cover. Magnetic source depths have previously been calculated as part of geothermal investigations in areas, such as the Nupe Basin in Nigeria (Nwankwo et al. 2009) and East Anatolia in Turkey at $20 \pm 5 \mathrm{~km}$ (Bektas et al. 2007). In their study, Salem et al. (2000) computed shallow magnetic sources at depths ranging from 0.76 to $2.14 \mathrm{~km}$ and curie point depths in the 10-km range for the Northern Red Sea area of Egypt in the northern part of Africa. Aeromagnetic survey data at various scales and sampling intervals were found to exhibit well-defined power-law behaviour (Pilkington and Todoeshuck 1993). The power density spectrum is the Fourier transform of a function that is proportional to the radially averaged power spectrum RAPS, (Schlömer and Deussen 2010). Maus and Dimri (1996) mentioned that depth often dominates the shape of the radially averaged power spectrum of magnetic data. The method derived by Spector and Grant (1970) was then used to estimate depths directly from the radially averaged power spectrum (Maus and Dimri 1996). The radially averaged energy is the spectral density (energy), averaged for all grid elements for particular wavenumbers. The energy was normalised by subtracting the log of the average spectral density (Oasis Geosoft Montaj 2014). 
In the computation of spectral energies, the data windows should have dimensions, $L$ that ensure that the computed depths are within and more that the value of, $L / 2 \pi$ to improve the depth resolution from spectral analysis (Nwankwo 2014). Abraham et al. (2014), however, argued that dimensions of $L$ ranging from 40, 41, 130, 150, and $222 \mathrm{~km}$ have been applied to determine depths of $10,15,30,32$, and $46 \mathrm{~km}$, respectively, on several case studies. Nwankwo et al. (2009) previously obtained a depth of $30 \mathrm{~km}$ from the analysis of a data set with an $L$ of $45 \mathrm{~km}$. Nonetheless, deeper magnetic sources affect long crustal magnetic field and that the estimation of the depth to the bottom of magnetic sources requires magnetic data that cover broader areas with dimensions that are longer than ten times the depth extent of magnetic sources to provide accurate estimates (Ravat et al. 2007; Bouligand et al. 2009). Therefore, larger data window are applied in this work.

Other geophysical methods that have been used to determine depths in the study area included the following:

- Durheim et al. (1992) processed seismic reflection data and delineated prominent reflectors in the 10-km depth range for an area located in the Soutpansberg Basin.

- De Beer and Stettler (1992) analysed geoelectrical, gravity, and aeromagnetic data for the southern margin of the Limpopo Mobile Belt, in the vicinity of the southern part of the Soutpansberg Basin and obtained lithological depths in the 10-km range.

- Gwavava and Ranganai (2009) modelled from gravity data, a top layer $8 \mathrm{~km}$ thick, consisting of granite, mafic greenstone, and meta-sediments for an area located to the north of the study area, in the southern part of the Zimbabwe Craton.

- Khoza et al. (2013) analysed magneto-telluric data for a profile across the Soutpansberg and reported a volcano-sedimentary sequence with a thickness of $7 \mathrm{~km}$.

The analysis of spectra of aeromagnetic data was carried out, because there was no evidence of published Curie depth determination for the whole Basin. The analysis of depths using the spectral approach was reported to take into consideration the utilisation of larger aeromagnetic data sets (Nwankwo et al. 2009). A major limitation of spectral analysis is, however, caused by magnetic anomalies that are only partly included in the data window that degrade the estimated spectrum (Tanaka et al. 1999). Okubo and Matsunaga (1994) compared the forward modelling of single magnetic profiles to spectral analysis of aeromagnetic data for Eastern Japan and concluded that the later was not affected by localised magnetic anomalies and that the statistical resolution of spectra could be improved by the stacking of multiple magnetic profile data. Okubo and Matsunaga (1994) showed that forward modelling of magnetic profile data does not produce unique solutions of the basal depth, as at least, three different depth models were deduced from the modeling of one profile.

The Centroid method is used for the determination of depths from the low and high wavenumber and regions of the azimuthally averaged frequency-scaled Fourier spectra (Ravat et al. 2007). Guimarães et al. (2013) deduced that the Centroid method was useful for delineating deep sources after computing at depths of $\pm 40 \mathrm{~km}$ for the Tocantins Province, Brazil. Bansal and Anand (2013) concluded that the Centroid method was robust for the determination of depths to the bottom of magnetic sources 
in their analysis of aeromagnetic data for Central India. Tanaka (2007) used the Centroid method to estimate the regional thermal structure beneath the Kamchatka Peninsula from only the computed depths to the centroid. The fundamental advantage of the spectrum analysis of a magnetic anomaly is that estimates of the top and the centroid of a magnetic source can be obtained with simple assumptions of the dimension of magnetic anomalies (Tanaka et al. 1999).

Nwankwo et al. (2009) used the Spectral Peak method to determine source depths from the analysis of the spectral peak and the gradient of the low wave number region of the power spectrum. The spectral peak method only applies where a peak in the power spectrum is identified (Nwankwo et al. 2009). A short coming of the spectral peak method is that the peak observed at low wave numbers, which is important in the estimation of the depth to the bottom of magnetic sources, is often not observed or only constrained by a few points in the radial power spectrum (Bouligand et al. 2009).

The Euler deconvolution approach is a depth determination technique that assumes no specific geological model by applying a structural index (SI) (Dewangan et al. 2007). The Euler deconvolution method is frequently used technique for generating the initial estimates of source locations from potential field data (Cooper 2009). El Dawi et al. (2004) concluded that the Euler deconvolution approach was used widely in automatic aeromagnetic interpretations, because it did not require any prior knowledge of the source magnetization direction and interpretation model. The method was not used as a stand-alone technique, because it was reported by Cooper (2009) to produce a large variation of solutions.

\section{Methods}

The processing of the data involved filtering by reduction to the pole (RTP) (Fig. 2) and removal of the geomagnetic gradient using the International Geomagnetic Reference Field (IGRF) for June 1973 (Table 1). Prior to the generation of the power spectrum, the data were converted from the space to the frequency domain using a Fourier transform algorithm.

Ravat et al. (2007) stated conditions that are required to ensure that correct spectral depths are determined as follows:

- Using a large window size of which dimensions are approximately ten times the expected depths;

- Investigating depths using different window size data blocks utilising IGRF-corrected magnetic data;

- Avoiding filtering data as this could lead to the modification of the low wavenumber part of the spectra thus altering the bottom depth estimates.

Two approaches were selected and used to determine depth: the Centroid method and the Euler deconvolution method. The Euler deconvolution method was used for the comparison of estimates of the depth to the basement $Z_{\mathrm{t}}$ to results obtained from the Centroid method.

The first approach involved the application of the Centroid method (Ravat et al. 2007; Nwankwo et al. 2009). The block sizes were chosen to ensure that spectral signatures 


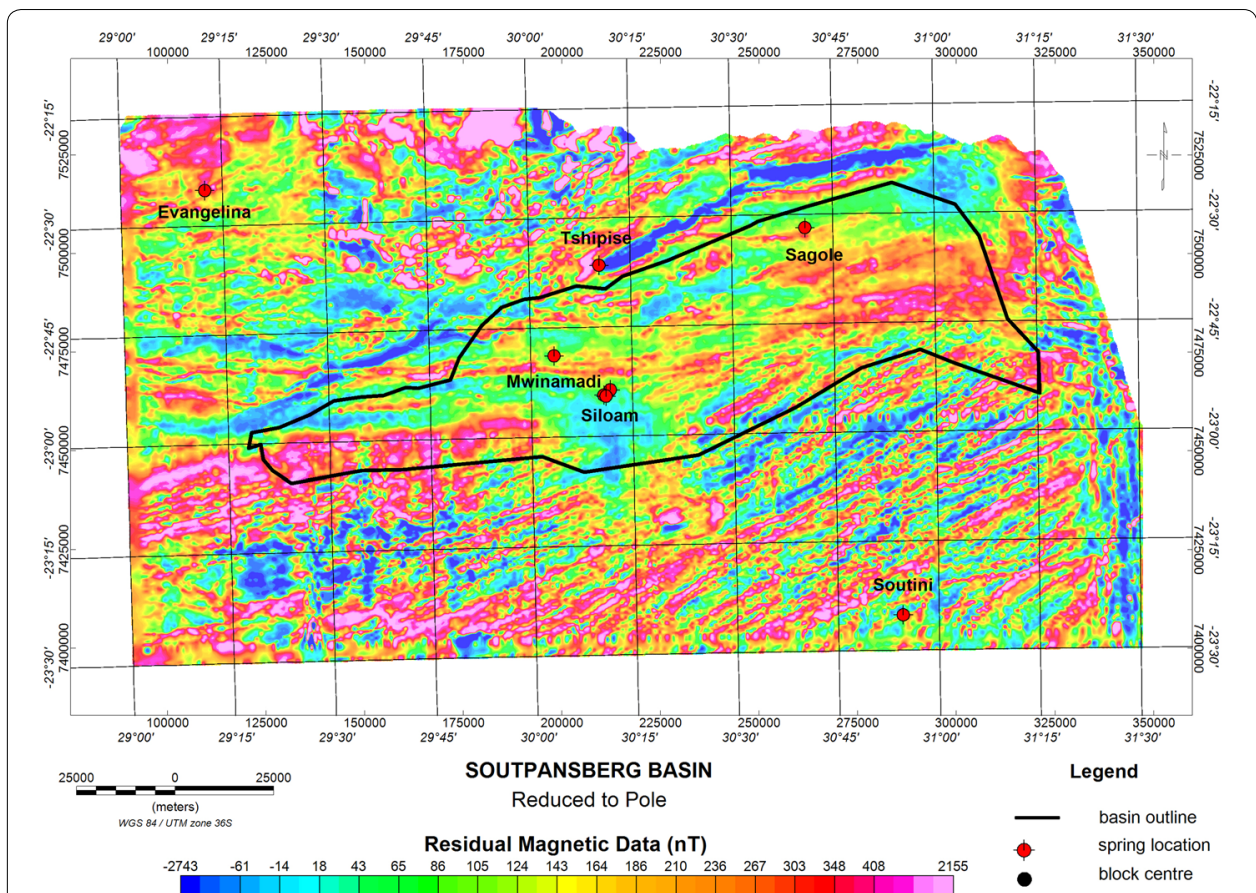

Fig. 2 Reduced-to-pole magnetic data showing the outline of the Soutpansberg Basin and springs as red symbols

Table 1 Magnetic field components

\begin{tabular}{lll}
\hline Item & Magnetic field component & Value \\
\hline 1 & Survey date & $06 / 1973$ \\
2 & Declination (decimal degrees) & -13.81 \\
3 & Inclination (decimal degrees) & -60.82 \\
4 & Total field (nT) & $31,590.81$ \\
5 & Magnetic model & IGRF \\
6 & Latitude (decimal degrees) & -22.90 \\
7 & Longitude (decimal degrees) & 30.19 \\
8 & Flight height $(\mathrm{m})$ & 150.00 \\
\hline
\end{tabular}

across the approximate $7-\mathrm{km}$ basin width were incorporated in the depth determinations. The use of multiple window sizes was to highlight the confidence in larger window sizes that would satisfy the condition of a curie point depth (CPD) that approximated $L / 2 \pi$ (Nwankwo 2014). The 51- and 103-km window sizes were used to generate 36 and 14 data points, respectively, that enabled the production of depth contour maps. The largest window size with $L$ of $129 \mathrm{~km}$ and six data points ensured that spectral signatures were preserved. The authors, therefore, utilised three window sizes to verify discussions on the choice of window sizes that supported the use various and larger window sizes for the spectral analyses of data for depth determinations (Nwankwo 2014; Abraham et al. 2014). 
The radially averaged power spectrum (RAPS) was generated from the transformed airborne magnetic data. Graphs of the power spectra versus the reciprocal of the wavelength were generated, with the wavenumber (1/wavelength) on the horizontal axis and the spectral energy on the vertical axis. The parts of the graph that is sub-parallel to the horizontal axis represent contributions from shallow and near-surface sources. The parts of the graphs that are sub-parallel to the vertical axis represent deeper sources with higher wavelength anomalies.

The depth to the magnetic source, $Z_{\mathrm{b}}$, is determined from the estimate of the depths to the centroid $Z_{\mathrm{o}}$ (Fig. 3) and top $Z_{\mathrm{t}}$ (Fig. 4), where the depths are obtained from the slope of the RAPS in the low and high wavenumber and regions, respectively (Ravat et al. 2007).

The Centroid method is made up of three (3) equations, that is:

The depth to the top, $Z_{\mathrm{t}}$ is obtained from fitting a line through the high wavenumber part of the RAPS using Eq. (1), where $P$ is the power density spectra, $k$ is wavenumber, and $B$ is a constant (Dolmaz et al. 2005; Lin et al. 2005; Bektas et al. 2007; Eletta and Udensi 2012)

$$
\ln \left(P(k)^{1 / 2}\right)=B-|k| Z_{\mathrm{t}}
$$

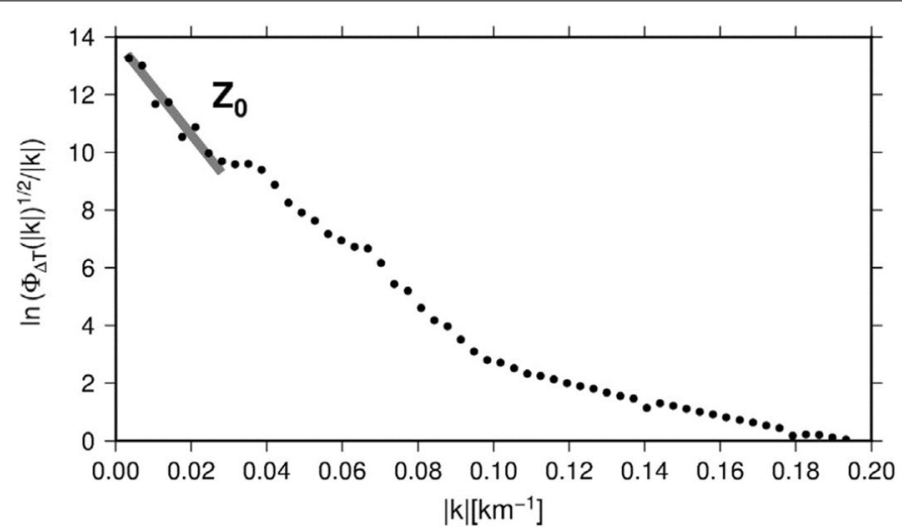

Fig. 3 Example of spectra for the estimation of the depth of the centroid, $Z_{0}$, of magnetic sources (Hsieh et al. 2014)

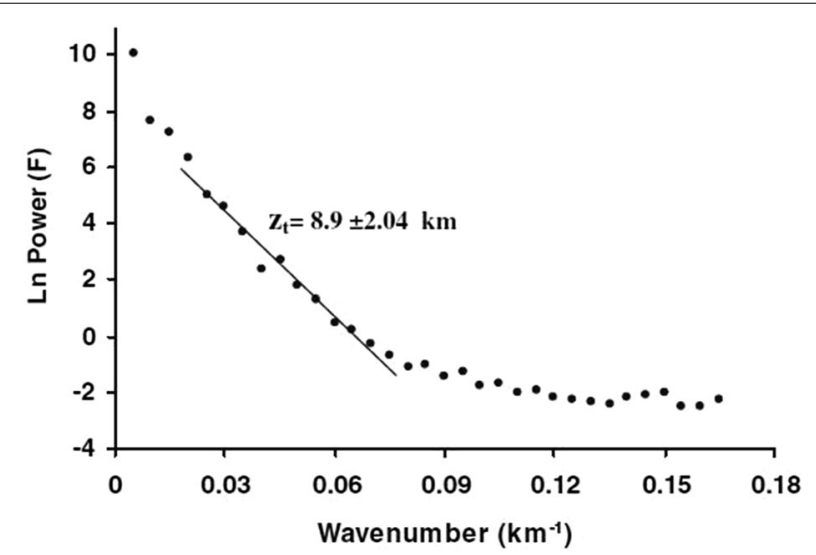

Fig. 4 Example of spectra for the estimation of the depth to the top of source, $Z_{t}$ (Bektas et al. 2007) 
The depth to the centroid, $Z_{\mathrm{o}}$ is obtained by fitting a straight line through the low wavenumber part of the frequency scaled, RAPS using Eq. (2), where $P$ is the power density spectra, $k$ is a wavenumber, and $A$ is a constant (Dolmaz et al. 2005; Lin et al. 2005; Bektas et al. 2007; Eletta and Udensi 2012)

$$
\ln \left(P(k)^{1 / 2} / k\right)=A-|k| Z_{\mathrm{o}}
$$

The basal depth, CPD, $Z_{\mathrm{b}}$ is computed using Eq. (3), where $Z_{\mathrm{o}}$ is the depth to the centroid and $Z_{\mathrm{t}}$ is the depth to the top of a geological body (Ravat et al. 2007; Eletta and Udensi 2012).

$$
Z_{\mathrm{b}}=2 Z_{\mathrm{o}}-Z_{\mathrm{t}}
$$

The application of Eq. 3 was being carried after making two different spectral plots using Eqs. 1 and 2 for the estimation of the depths to the top $\left(Z_{t}\right)$ and centroid $\left(Z_{\mathrm{o}}\right)$ of magnetic sources for each block.

The Euler deconvolution approach was applied to an area with dimensions of 80 by $80 \mathrm{~km}$, located in the central part of the Soutpansberg Basin to compare depth estimates to results obtained from the centroid method for the depth to the basement $Z_{\mathrm{t}}$. The area included the Siloam hot spring cluster. To prevent the Euler deconvolution process from being automatic, a structural index (SI) was applied. Komolafe (2010) provided the following sequence for calculating Euler deconvolution: reduction to pole, calculation of horizontal and vertical gradients of magnetic field data, frequency-domain calculation, choice of window sizes, and finally, SI calculation. The structural index is a measure of the degree of change through the distance of the field (Reid et al. 1990). The SI that yields the tightest clusters can be considered the correct one (Dewangan et al. 2007). The use of incorrect SI values produces scatter and bias in the calculated depths (Reid et al. 1990). Mushayandebvu et al. (2001) noted that an SI of 0 is used for geological contacts and that an SI of 1 is used for a dyke contact. Reynolds (2011) stated that the SI value for vertical geological contacts and sills was 0 and 1 , respectively.

The Euler depth solutions are computed from Eq. 4, from the total magnetic field strength at any point in terms of the gradient of the total field in terms of the gradient of the total field, expressed in Cartesian coordinates and related to different magnetic sources in terms of the SI, $N$ (Reynolds 2011)

$$
\left(X-X_{\mathrm{o}}\right) \frac{d T}{d X}+\left(Y-Y_{\mathrm{o}}\right) \frac{d T}{d Y}-Z_{\mathrm{t}} \frac{d T}{d Z}-=N(B-T) .
$$

where $X_{\mathrm{o}}, Y_{\mathrm{o}}$, and $Z_{\mathrm{t}}$ are the unknown coordinates of the magnetic source, whose total field intensity $T$ and regional field value $B$ are measured at a point $(X, Y, Z)$ and $N$ is the SI (Reynolds 2011). The Euler deconvolution process involves the evaluation of Eq. 4 to generate seven equations that are solved for the three unknowns using a least squares procedure, determining the depth to the magnetic source $Z_{\mathrm{t}}$. Euler deconvolution is an automated function for determining the depth to source from profiles. The Euler deconvolution was computed using an automated Geosoft software module that is based on a paper by the Mushayandebvu et al. (2001). 


\section{Results}

There is a dense concentration of hot springs in the central part of the Soutpansberg basin. The reduced-to-pole (RTP) airborne magnetic data show that the same area has a swarm of northeast-trending dykes and east-to-west and northwest-oriented geological structures. The major magnetic lineaments in the Soutpansberg Basin are oriented north-east and north-south (Fig. 2). The computations of magnetic source depths from the radial power spectrum for blocks with square dimensions of 51 by $51 \mathrm{~km}, 103$ by $103 \mathrm{~km}$, and 129 by $129 \mathrm{~km}$ are presented in this section (Figs. 5, 6, 7).

The RAPS graph, Log (Power) versus Wavenumber, for Block 3, located in the central part of the Soutpansberg Basin with a dimension $L$ of $129 \mathrm{~km}$ is presented as an example (Fig. 8). The part of the power spectra that is parallel to the horizontal axis shows the average contribution of shallow sources, used for computing the depth to the top of magnetic sources $Z_{\mathrm{t}}$ (Fig. 9). The frequency-scaled power spectrum of the deeper magnetic sources is parallel to the vertical axis as well as the corresponding depth spectrum graph, used for computing the depth to the centroid $Z_{\mathrm{o}}$ (Fig. 10).

The depth results obtained from the analysis of the data from 51 by $51-\mathrm{km}$ data sets are shown in Table 2. Illustrated are the top of magnetic bodies $Z_{\mathrm{t}}$, centroid of the basement $Z_{\mathrm{o}}$, and CPD $Z_{\mathrm{b}}$, with minimum and maximum value ranges of 3.91-5.53, 6.82-8.84, and $9.28-12.16 \mathrm{~km}$, respectively (Table 2). The average depth values for $Z_{\mathrm{t}}, Z_{\mathrm{o}}$, and $Z_{\mathrm{b}}$ were $4.66 \pm 0.44,7.74 \pm 0.59$, and $10.81 \pm 0.76 \mathrm{~km}$, respectively (Table 2 ).

A west-to-east profile $\mathrm{AB}$, along latitude $23^{\circ}$ (South) for blocks with $L=51 \mathrm{~km}$, defined the depths $Z_{\mathrm{t}}, Z_{\mathrm{o}}$, and $Z_{\mathrm{b}}$ generally getting shallower to the east, with a trough in the centre of the Basin at longitude $30.25^{\circ}$ (East) (Fig. 11).

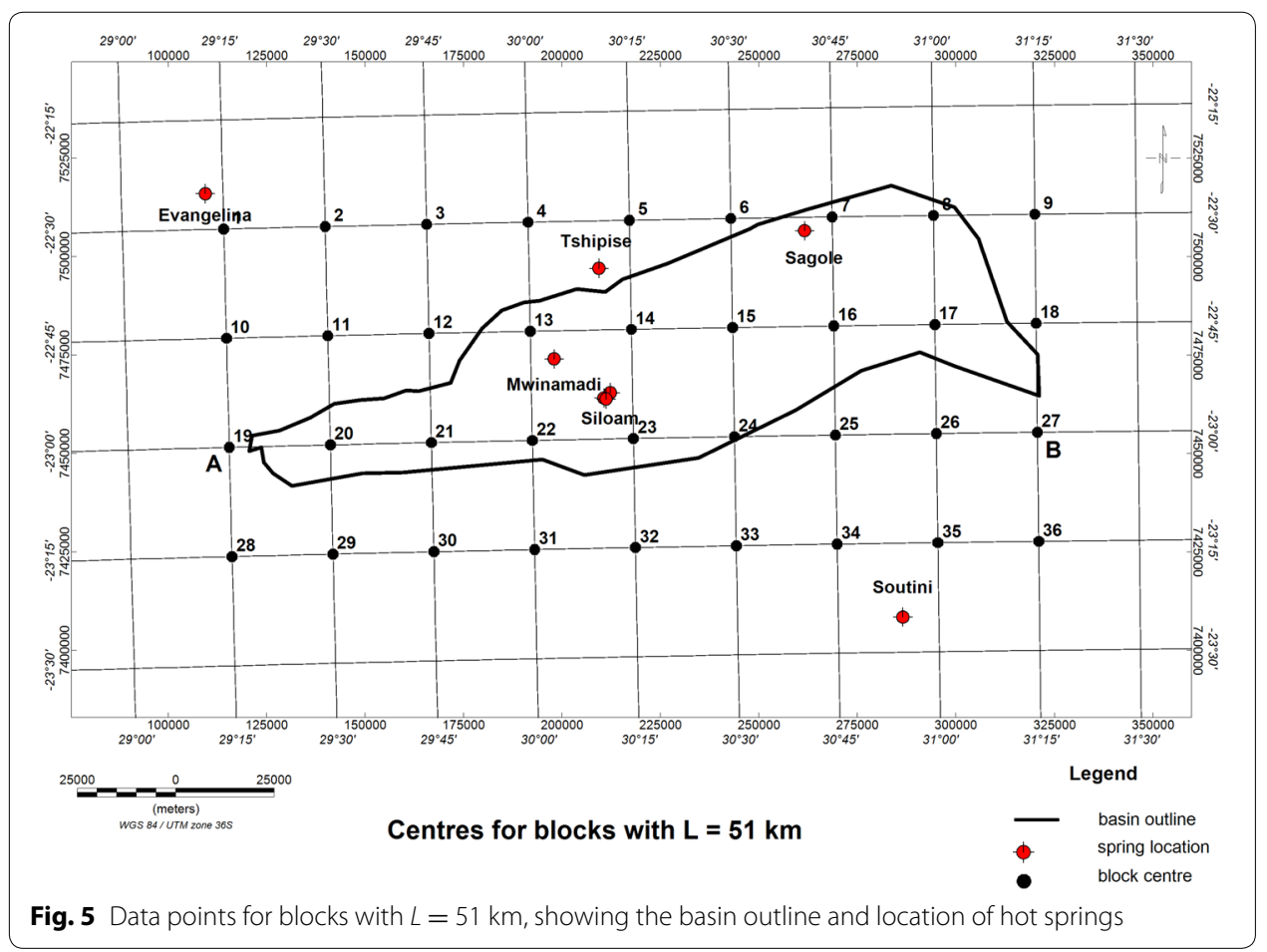




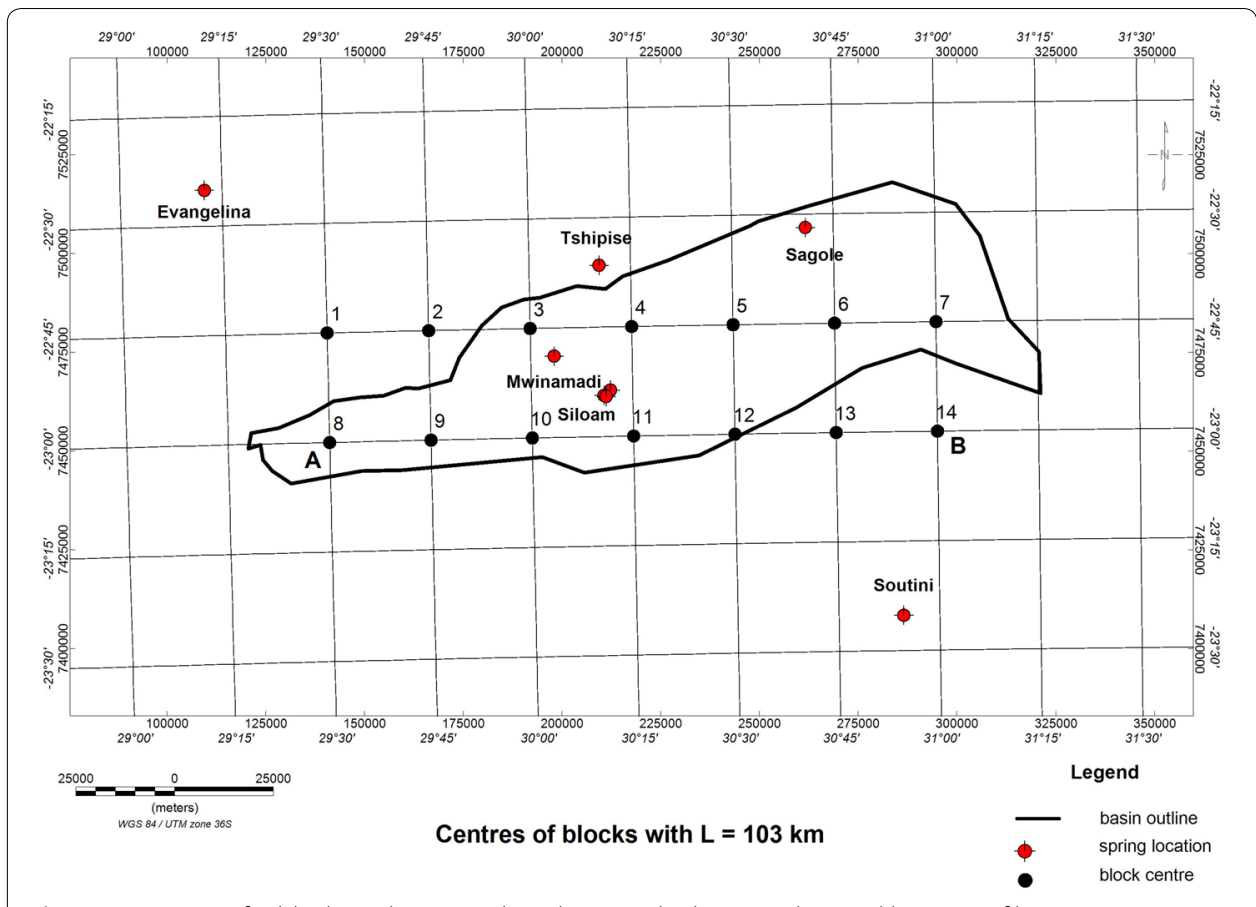

Fig. 6 Data points for blocks with $L=103 \mathrm{~km}$, showing the basin outline and location of hot springs

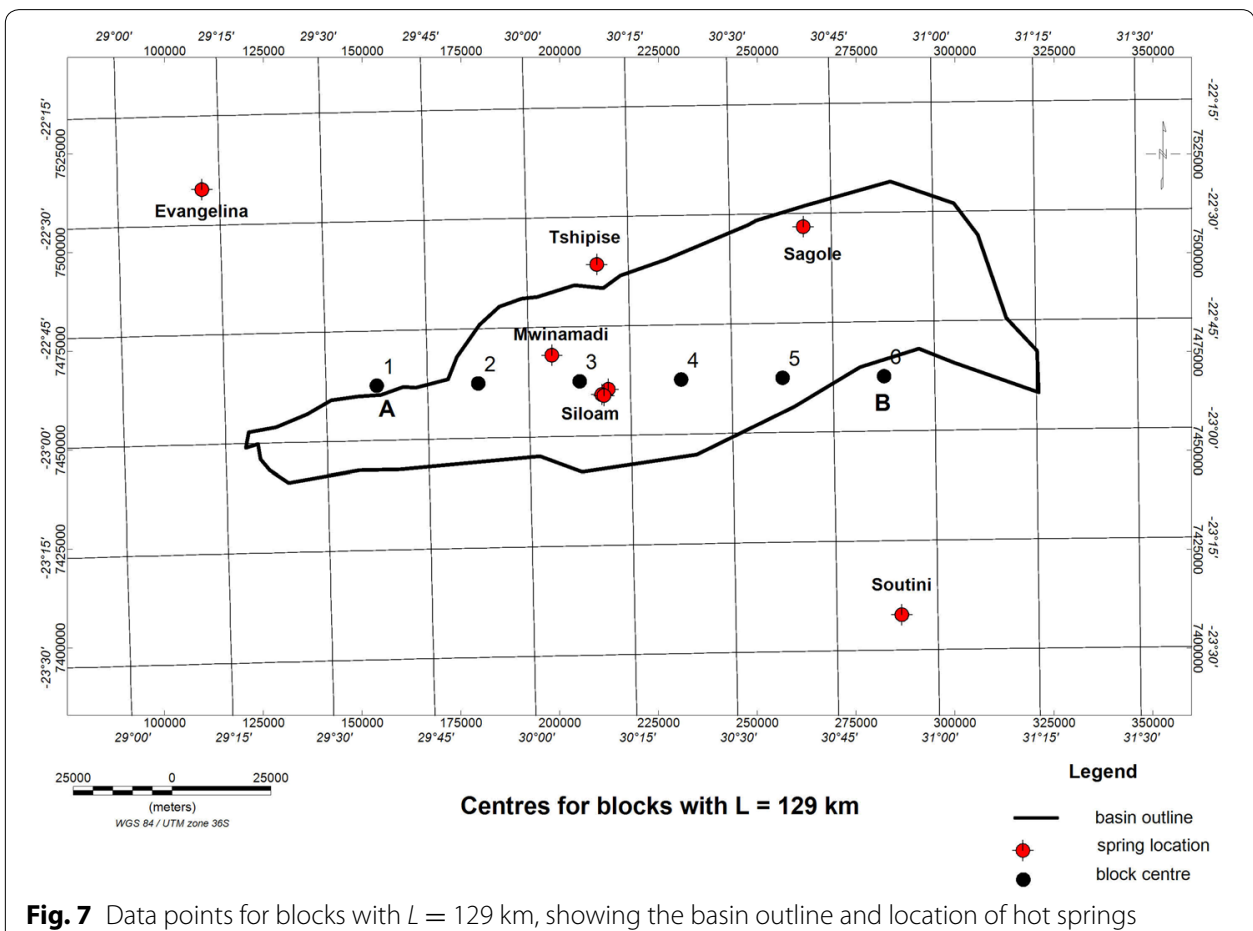

The results for the analysis of the data from 103 by 103-km blocks are listed in Table 3. The minimum and maximum depth ranges for $Z_{\mathrm{t}}, Z_{\mathrm{o}}$, and $Z_{\mathrm{b}}$ were 4.34-5.18, 7.36-8.56, and $10.38-11.94 \mathrm{~km}$, respectively (Table 3 ). The average depth values for $Z_{\mathrm{t}}, Z_{\mathrm{o}}$, and $Z_{\mathrm{b}}$ were $4.76 \pm 0.29,7.94 \pm 0.41$, and $11.12 \pm 0.53 \mathrm{~km}$, respectively (Table 3 ). 


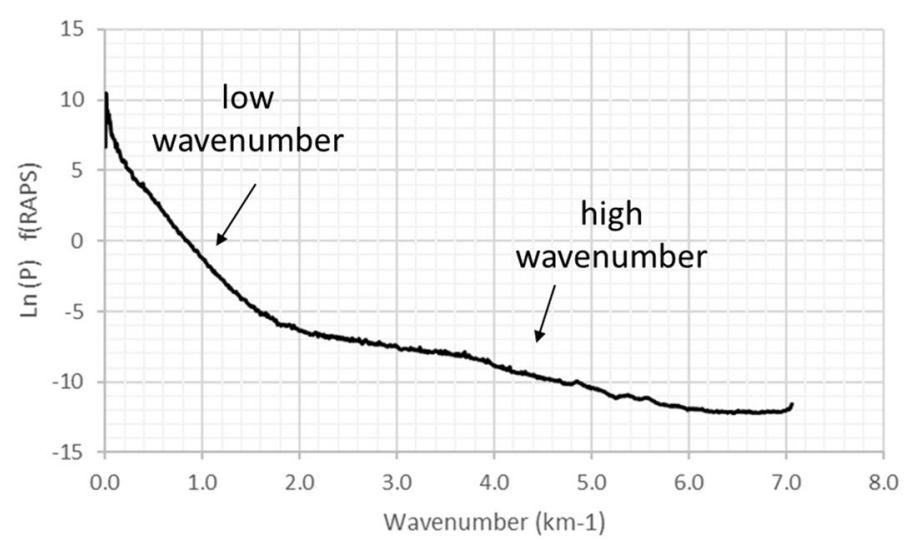

Fig. 8 Radially averaged power spectrum graph for block 3 with a dimension L of $129 \mathrm{~km}$ showing parts that are parallel horizontal and vertical axes

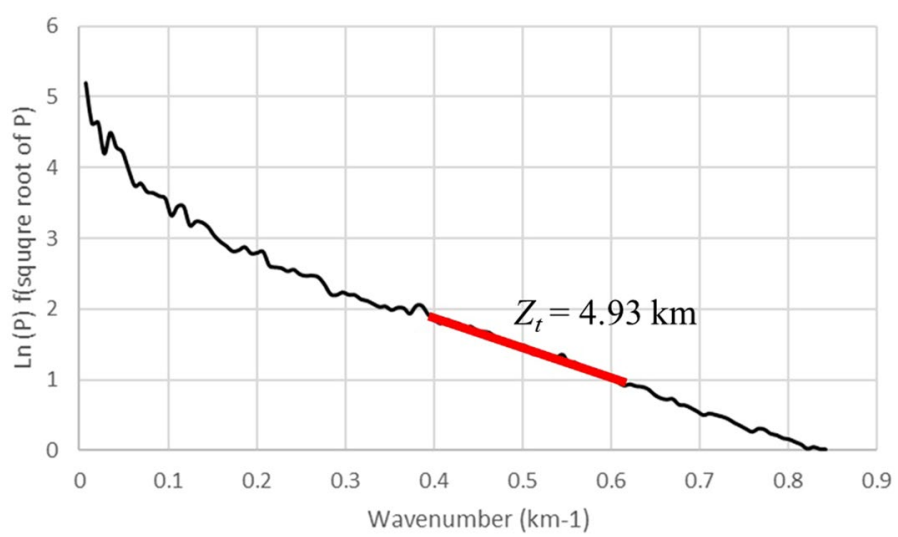

Fig. 9 Power spectrum graph for block 3 with a dimension $L$ of $129 \mathrm{~km}$ the gradient for determining, $Z_{\mathrm{t}}$, the depth to the top of magnetic source

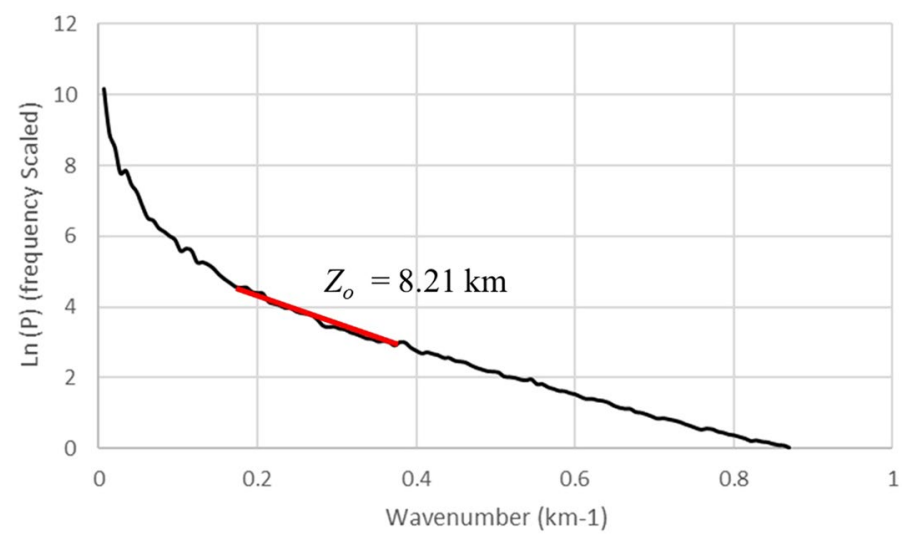

Fig. 10 Frequency-scaled-averaged power spectrum graph for block 3 with a dimension $L$ of $129 \mathrm{~km}$ and the gradient for determining, $Z_{0}$, the depth to the centroid 
Table 2 Depths $Z_{t}, Z_{o}$, and $Z_{b}$ for the 51 by 51-km blocks

\begin{tabular}{|c|c|c|c|c|c|c|c|}
\hline Row & $L(\mathrm{~km})$ & Block & Longitude & Latitude & $Z_{\mathrm{t}}(\mathrm{km})$ & $Z_{\mathrm{o}}(\mathrm{km})$ & $Z_{\mathrm{b}}(\mathrm{km})$ \\
\hline 1 & 51 & 1 & 29.25 & -22.50 & 4.97 & 8.07 & 11.18 \\
\hline 1 & 51 & 2 & 29.50 & -22.50 & 4.67 & 7.89 & 11.10 \\
\hline 1 & 51 & 3 & 29.75 & -22.50 & 5.15 & 8.47 & 11.79 \\
\hline 1 & 51 & 4 & 30.00 & -22.50 & 5.12 & 8.35 & 11.59 \\
\hline 1 & 51 & 5 & 30.25 & -22.50 & 5.19 & 8.22 & 11.25 \\
\hline 1 & 51 & 6 & 30.50 & -22.50 & 5.33 & 8.70 & 12.06 \\
\hline 1 & 51 & 7 & 30.75 & -22.50 & 5.53 & 8.84 & 12.15 \\
\hline 1 & 51 & 8 & 31.00 & -22.50 & 5.40 & 8.78 & 12.16 \\
\hline 1 & 51 & 9 & 31.25 & -22.50 & 5.03 & 8.33 & 11.64 \\
\hline 2 & 51 & 10 & 29.25 & -22.75 & 4.68 & 7.66 & 10.64 \\
\hline 2 & 51 & 11 & 29.50 & -22.75 & 5.10 & 8.41 & 11.73 \\
\hline 2 & 51 & 12 & 29.75 & -22.75 & 4.88 & 8.38 & 11.89 \\
\hline 2 & 51 & 13 & 30.00 & -22.75 & 4.90 & 8.01 & 11.11 \\
\hline 2 & 51 & 14 & 30.25 & -22.75 & 5.16 & 8.18 & 11.20 \\
\hline 2 & 51 & 15 & 30.50 & -22.75 & 4.93 & 7.95 & 10.96 \\
\hline 2 & 51 & 16 & 30.75 & -22.75 & 4.73 & 7.58 & 10.43 \\
\hline 2 & 51 & 17 & 31.00 & -22.75 & 4.52 & 7.37 & 10.22 \\
\hline 2 & 51 & 18 & 31.25 & -22.75 & 4.54 & 6.91 & 9.28 \\
\hline 3 & 51 & 19 & 29.25 & -23.00 & 4.89 & 7.99 & 11.09 \\
\hline 3 & 51 & 20 & 29.50 & -23.00 & 4.73 & 7.86 & 10.99 \\
\hline 3 & 51 & 21 & 29.75 & -23.00 & 4.63 & 7.70 & 10.78 \\
\hline 3 & 51 & 22 & 30.00 & -23.00 & 4.58 & 7.67 & 10.76 \\
\hline 3 & 51 & 23 & 30.25 & -23.00 & 4.81 & 7.93 & 11.05 \\
\hline 3 & 51 & 24 & 30.50 & -23.00 & 4.43 & 7.33 & 10.24 \\
\hline 3 & 51 & 25 & 30.75 & -23.00 & 3.97 & 6.88 & 9.79 \\
\hline 3 & 51 & 26 & 31.00 & -23.00 & 3.91 & 6.82 & 9.74 \\
\hline 3 & 51 & 27 & 31.25 & -23.00 & 4.25 & 7.20 & 10.15 \\
\hline 4 & 51 & 28 & 29.25 & -23.25 & 4.42 & 7.59 & 10.77 \\
\hline 4 & 51 & 29 & 29.50 & -23.25 & 4.36 & 7.48 & 10.59 \\
\hline 4 & 51 & 30 & 29.75 & -23.25 & 4.43 & 7.47 & 10.52 \\
\hline 4 & 51 & 31 & 30.00 & -23.25 & 4.36 & 7.42 & 10.47 \\
\hline 4 & 51 & 32 & 30.25 & -23.25 & 4.14 & 7.10 & 10.07 \\
\hline 4 & 51 & 33 & 30.50 & -23.25 & 4.09 & 7.00 & 9.91 \\
\hline 4 & 51 & 34 & 30.75 & -23.25 & 3.92 & 6.84 & 9.75 \\
\hline 4 & 51 & 35 & 31.00 & -23.25 & 3.91 & 6.83 & 9.74 \\
\hline 4 & 51 & 36 & 31.25 & -23.25 & 4.31 & 7.31 & 10.30 \\
\hline \multicolumn{5}{|c|}{ Minimum depth (km) } & 3.91 & 6.82 & 9.28 \\
\hline \multicolumn{5}{|c|}{ Average depth (km) } & 4.66 & 7.74 & 10.81 \\
\hline \multicolumn{5}{|c|}{ Maximum depth (km) } & 5.53 & 8.84 & 12.16 \\
\hline \multicolumn{5}{|c|}{ Standard deviation of mean $(\mathrm{km})$} & 0.44 & 0.59 & 0.76 \\
\hline \multicolumn{5}{|c|}{ Standard deviation of mean (\%) } & 9.5 & 7.6 & 7.0 \\
\hline
\end{tabular}

The plot of depth values along a west-to-east profile $\mathrm{AB}$, along latitude $23^{\circ}$ (South) south, shows the depths generally getting shallower to the east, with a trough defined in the central part of the basin at longitude 30.25 (East) (Fig. 12).

The results for the analysis of the data from 129 by $129-\mathrm{km}$ data sets are in Table 4 . The depth ranges for $Z_{\mathrm{t}}, Z_{\mathrm{o}}$, and $Z_{\mathrm{b}}$ were 4.63-4.99, 7.86-8.26, and $11.09-11.53 \mathrm{~km}$, respectively (Table 4). The average values for $Z_{\mathrm{t}}, Z_{\mathrm{o}}$, and $Z_{\mathrm{b}}$ were $4.83 \pm 0.15,8.08 \pm 0.17$, and $11.33 \pm 0.19 \mathrm{~km}$, respectively (Table 4). 


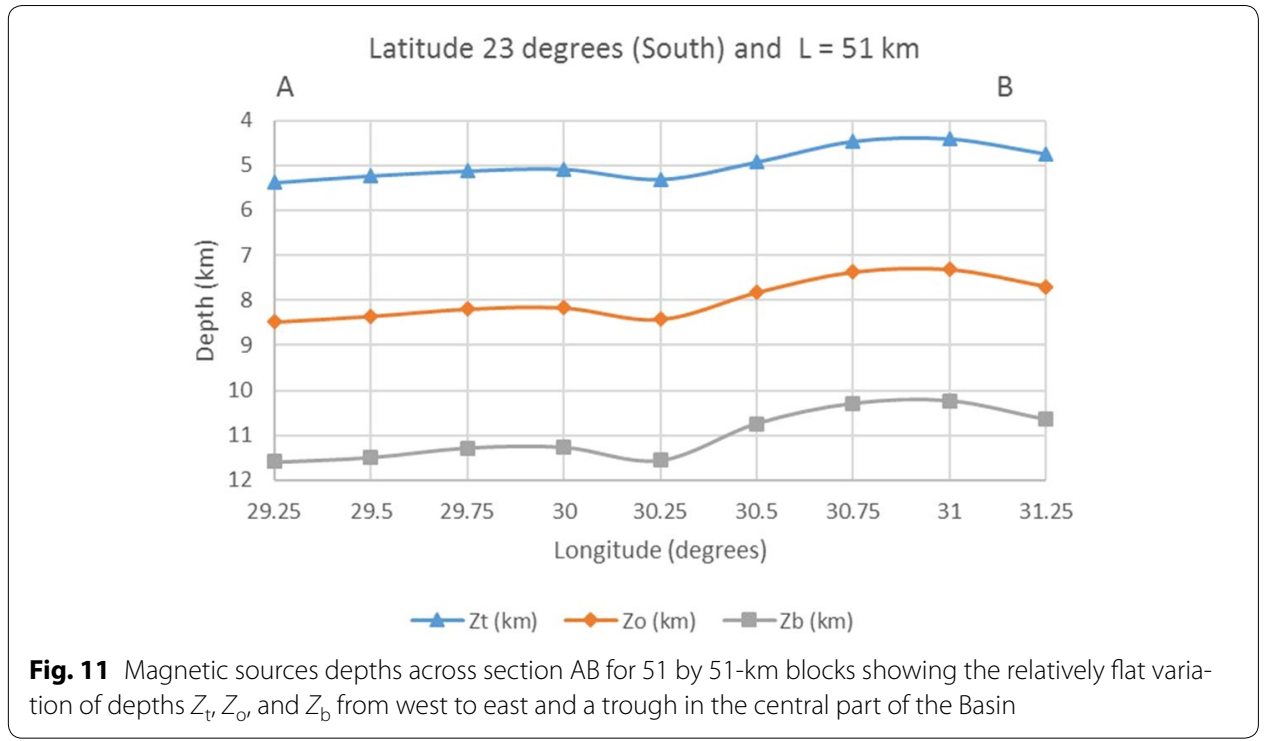

Table 3 Depths $Z_{\mathrm{t}}, Z_{\mathrm{o}}$, and $Z_{\mathrm{b}}$ for the 103 by 103-km blocks

\begin{tabular}{|c|c|c|c|c|c|c|c|}
\hline Row & $L(\mathrm{~km})$ & Block & Longitude & Latitude & $Z_{\mathrm{t}}(\mathrm{km})$ & $Z_{\mathrm{o}}(\mathrm{km})$ & $Z_{\mathrm{b}}(\mathrm{km})$ \\
\hline 1 & 103 & 1 & 29.50 & -22.75 & 5.18 & 8.56 & 11.94 \\
\hline 1 & 103 & 2 & 29.75 & -22.75 & 5.15 & 8.41 & 11.66 \\
\hline 1 & 103 & 3 & 30.00 & -22.75 & 5.14 & 8.46 & 11.77 \\
\hline 1 & 103 & 4 & 30.25 & -22.75 & 5.14 & 8.48 & 11.82 \\
\hline 1 & 103 & 5 & 30.50 & -22.75 & 4.83 & 8.09 & 11.34 \\
\hline 1 & 103 & 6 & 30.75 & -22.75 & 4.77 & 7.92 & 11.08 \\
\hline 1 & 103 & 7 & 31.00 & -22.75 & 4.73 & 7.94 & 11.14 \\
\hline 2 & 103 & 8 & 29.50 & -23.00 & 4.67 & 7.86 & 11.05 \\
\hline 2 & 103 & 9 & 29.75 & -23.00 & 4.63 & 7.82 & 11.01 \\
\hline 2 & 103 & 10 & 30.00 & -23.00 & 4.54 & 7.65 & 10.76 \\
\hline 2 & 103 & 11 & 30.25 & -23.00 & 4.56 & 7.71 & 10.85 \\
\hline 2 & 103 & 12 & 30.50 & -23.00 & 4.44 & 7.48 & 10.52 \\
\hline 2 & 103 & 13 & 30.75 & -23.00 & 4.34 & 7.36 & 10.39 \\
\hline 2 & 103 & 14 & 31.00 & -23.00 & 4.48 & 7.43 & 10.38 \\
\hline \multicolumn{5}{|c|}{ Minimum depth (km) } & 4.34 & 7.36 & 10.38 \\
\hline \multicolumn{5}{|c|}{ Average depth (km) } & 4.76 & 7.94 & 11.12 \\
\hline \multicolumn{5}{|c|}{ Maximum depth (km) } & 5.18 & 8.56 & 11.94 \\
\hline \multicolumn{5}{|c|}{ Standard deviation of mean (km) } & 0.29 & 0.41 & 0.53 \\
\hline \multicolumn{5}{|c|}{ Standard deviation of mean (\%) } & 6.1 & 5.1 & 4.7 \\
\hline
\end{tabular}

The plot of depth values for a west-to-east profile $\mathrm{AB}$, along latitude $22.875^{\circ}$ (South) south, shows the depths getting shallower to the east with a trough in the central part of the Basin at longitude $30.125^{\circ}$ (East) (Fig. 13).

The Euler deconvolution depth solutions indicate the presence of magnetic source clusters at depths between 2.0 and $3.0 \mathrm{~km}$ within the Basin outline (Fig. 14). The deepest source depths below $3.0 \mathrm{~km}$ are located at the central part of the basin and define anticline or a conical feature below the $2 \mathrm{~km}$ depth (Fig. 15). 


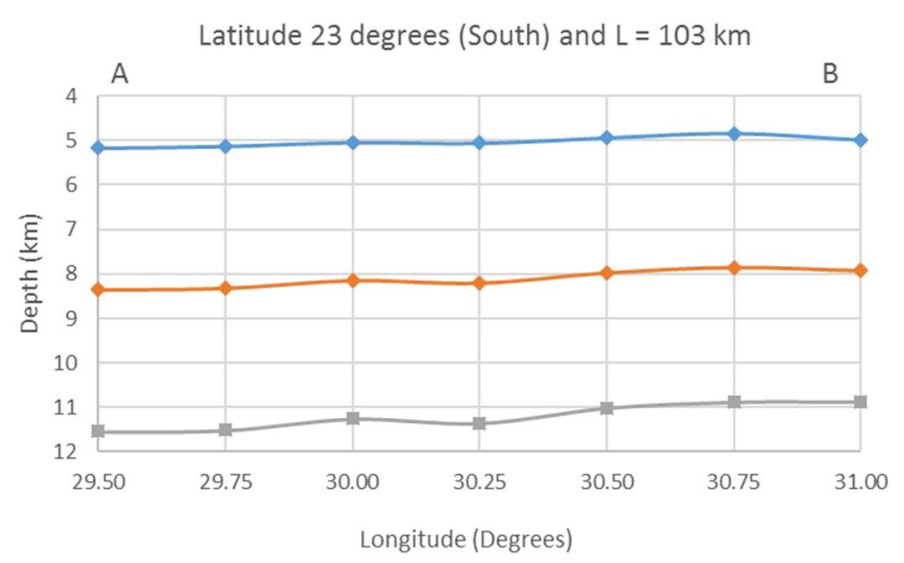

$\longrightarrow \mathrm{Zo}(\mathrm{km}) \rightarrow \mathrm{Zb}(\mathrm{km}) \longrightarrow \mathrm{Zt}(\mathrm{km})$

Fig. 12 Magnetic sources depths across section AB for 103 by 103-km blocks, showing a trough in the central part of the basin highlighted by the $Z_{\mathrm{o}}$ and $Z_{\mathrm{b}}$ profiles

Table 4 Depths $Z_{t}, Z_{o}$, and $Z_{b}$ for the 129 by $129-k m$ blocks

\begin{tabular}{|c|c|c|c|c|c|c|c|}
\hline Row & $L(\mathbf{k m})$ & Block & Longitude & Latitude & $Z_{\mathrm{t}}(\mathrm{km})$ & $Z_{\mathrm{o}}(\mathrm{km})$ & $Z_{\mathrm{b}}(\mathrm{km})$ \\
\hline 1 & 129 & 1 & 29.63 & -22.88 & 4.99 & 8.26 & 11.53 \\
\hline 1 & 129 & 2 & 29.88 & -22.88 & 4.94 & 8.20 & 11.46 \\
\hline 1 & 129 & 3 & 30.13 & -22.88 & 4.93 & 8.21 & 11.48 \\
\hline 1 & 129 & 4 & 30.38 & -22.88 & 4.84 & 8.09 & 11.33 \\
\hline 1 & 0 & 5 & 30.63 & -22.88 & 4.63 & 7.86 & 11.09 \\
\hline 1 & 129 & 6 & 30.88 & -22.88 & 4.66 & 7.89 & 11.11 \\
\hline \multicolumn{5}{|c|}{ Minimum depth (km) } & 4.63 & 7.86 & 11.09 \\
\hline \multicolumn{5}{|c|}{ Average depth (km) } & 4.83 & 8.08 & 11.33 \\
\hline \multicolumn{5}{|c|}{ Maximum depth $(\mathrm{km})$} & 4.99 & 8.26 & 11.53 \\
\hline \multicolumn{5}{|c|}{ Standard deviation of mean ( $\mathrm{km})$} & 0.15 & 0.17 & 0.19 \\
\hline \multicolumn{5}{|c|}{ Standard deviation of mean (\%) } & 3.2 & 2.1 & 1.7 \\
\hline
\end{tabular}

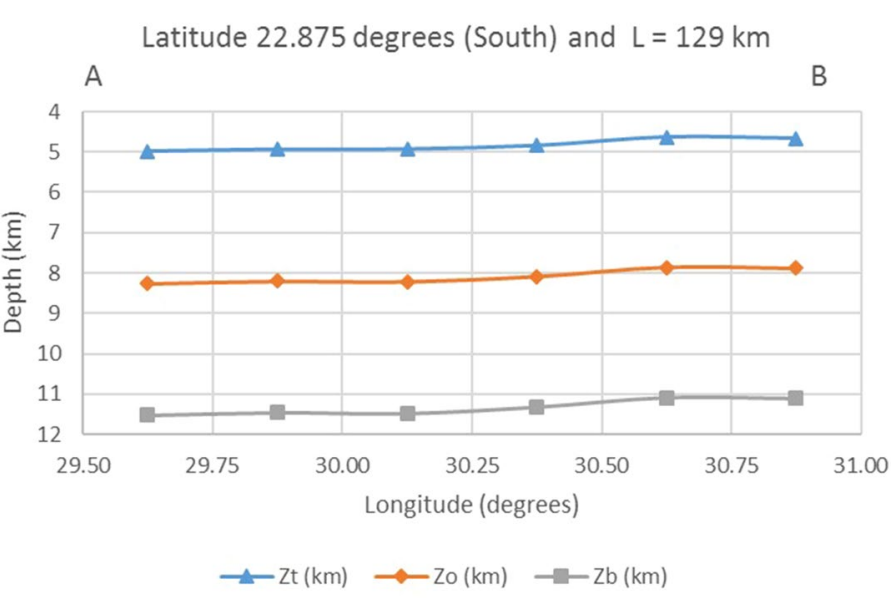

Fig. 13 Magnetic sources depths across section AB for 129 by 129-km blocks, showing a trough in the central part of the basin highlighted by the $Z_{\circ}$ and $Z_{b}$ profiles 


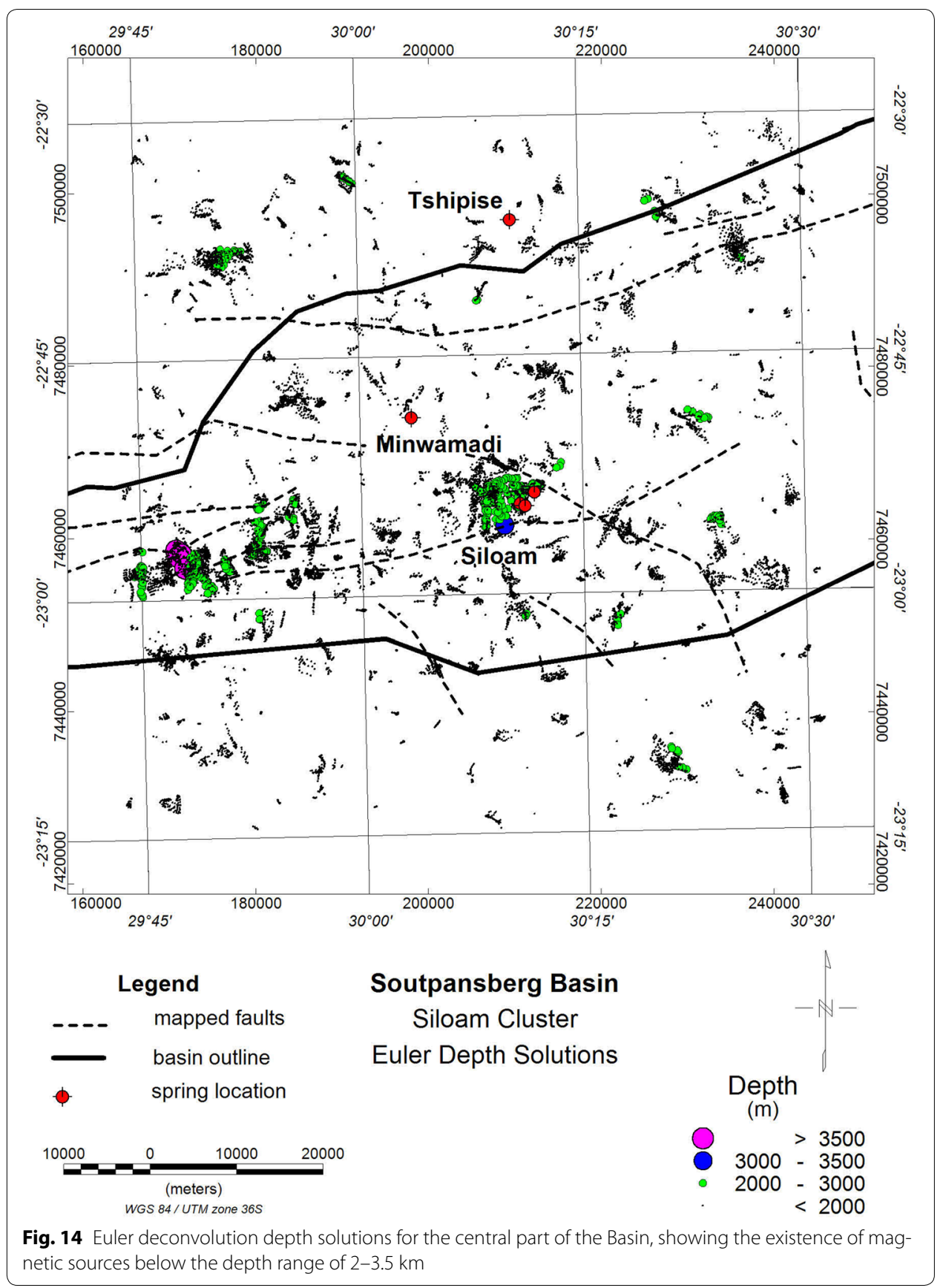

\section{Discussion}

A large population of short-wavelength features was found at depths from the surface to approximately $2 \mathrm{~km}$. There is an anticlinal magnetic source body in the central part of the basin at a depth of approximately $3.5 \mathrm{~km}$ as defined by results of the Euler deconvolution method.

The power spectra graphs of the aeromagnetic data for the Soutpansberg basin showed well-defined contributions from both shallow and deep seated magnetic sources. A trough at a depth below $7.5 \mathrm{~km}$ was defined by the contour of the depth to the centroid 


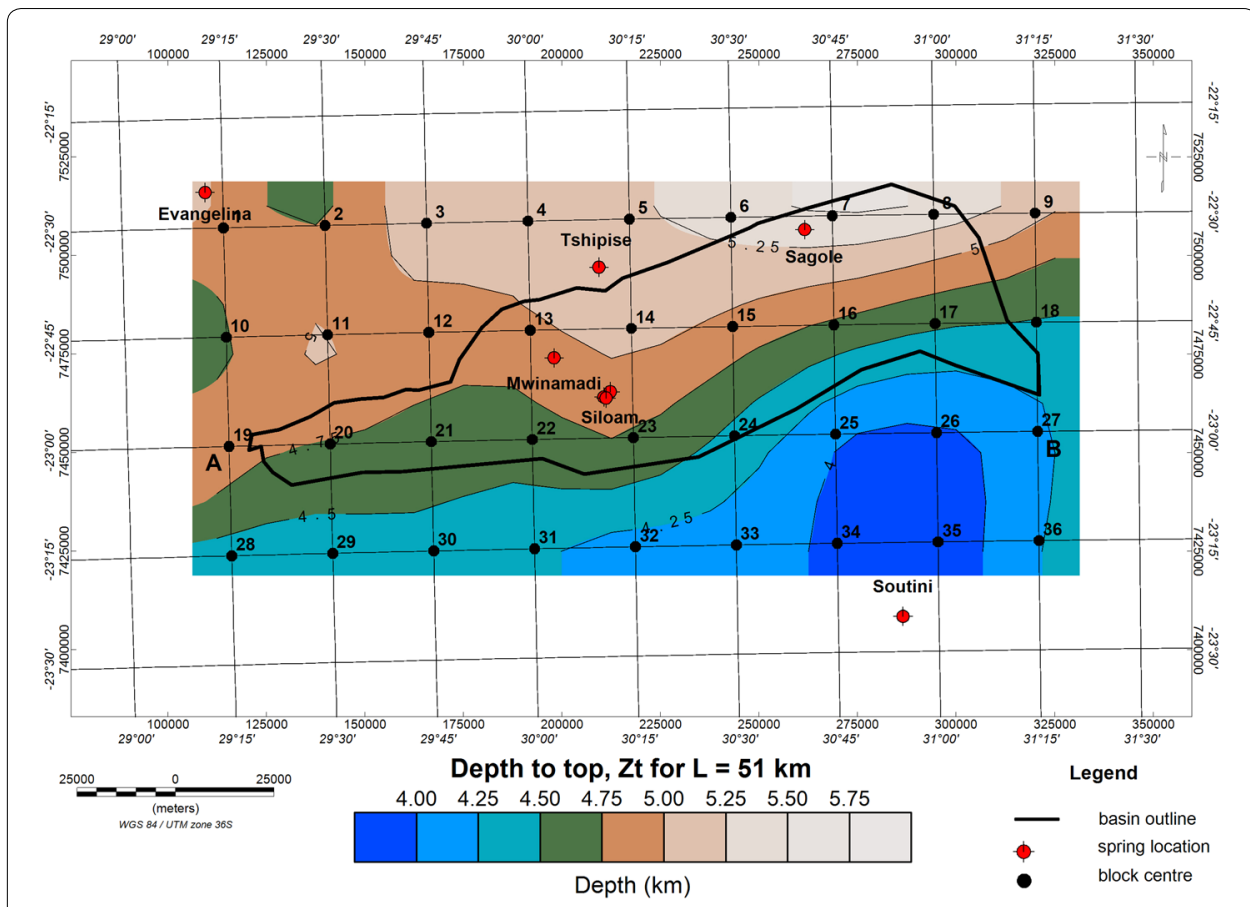

Fig. 15 Depth to the top $Z_{\mathrm{t}}$ for 51 by $51-\mathrm{km}$ blocks, showing contours oriented southwest to northeast within the Basin

Table 5 Comparison of average source depths $Z_{t}, Z_{0}$, and $Z_{b}$ that for square blocks with the $L$, dimension of 51,103 , and $129 \mathrm{~km}$

\begin{tabular}{|c|c|c|c|c|c|c|}
\hline \multirow{2}{*}{$\begin{array}{l}\text { Subsurface } \\
\text { zone }(\mathbf{k m})\end{array}$} & \multicolumn{3}{|c|}{ Block, $L$ dimension } & \multirow{2}{*}{$\begin{array}{l}\text { Mean } \\
\text { depth (km) }\end{array}$} & \multirow{2}{*}{$\begin{array}{l}\text { Variation of } \\
\text { mean }(+/-\mathrm{km})\end{array}$} & \multirow{2}{*}{$\begin{array}{l}\text { Variation of } \\
\text { mean }(+/-\%\end{array}$} \\
\hline & $51 \mathrm{~km}$ & $103 \mathrm{~km}$ & $129 \mathrm{~km}$ & & & \\
\hline$Z_{t}$ & 4.66 & 4.76 & 4.83 & 4.75 & 0.56 & 11.7 \\
\hline$Z_{0}$ & 7.74 & 7.94 & 8.08 & 7.92 & 0.74 & 9.4 \\
\hline$Z_{\mathrm{b}}$ & 10.81 & 11.12 & 11.33 & 11.09 & 0.96 & 8.6 \\
\hline
\end{tabular}

of the basement. The relatively deeper CPD occurred below the 11.1-km-depth contour. The depth contours were generally oriented southwest to northeast and parallel to the Limpopo Mobile Belt.

The research showed that the average depths to the top $\left(Z_{\mathrm{t}}\right)$, centroid $\left(Z_{\mathrm{o}}\right)$, and basal $\left(Z_{\mathrm{b}}\right)$ for the three block sizes with $L$ values of 51,103 , and $129 \mathrm{~km}$ were in the range $4.75 \pm 0.56$, $7.92 \pm 0.74$, and $11.09 \pm 0.96 \mathrm{~km}$, respectively (Table 5). The average depth values for $Z_{\mathrm{t}}, Z_{\mathrm{o}}$, and $Z_{\mathrm{b}}$ were comparable within $11.7,9.4$, and $8.6 \%$, respectively (Table 5 ).

The depths $Z_{\mathrm{t}}, Z_{\mathrm{o}}$, and $Z_{\mathrm{b}}$ for blocks with a dimension $L$ of $129 \mathrm{~km}$ were between $4.75-$ 5.0, 8.0-8.5, and 11.0-11.5 km, respectively, in the central part of the Basin with hot spring occurrences (Fig. 13).

The depth contours for blocks with a dimension $L$ of $51 \mathrm{~km}$ were generally oriented southwest to northeast with hot springs in the central part of the basin occurring within a zone with $Z_{\mathrm{t}}, Z_{\mathrm{o}}$, and $Z_{\mathrm{b}}$ depth ranges of 4.75-5.00 km (Fig. 15), 8.0-8.5 km (Fig. 16), and 11.0-11.5 km (Fig. 17), respectively. 


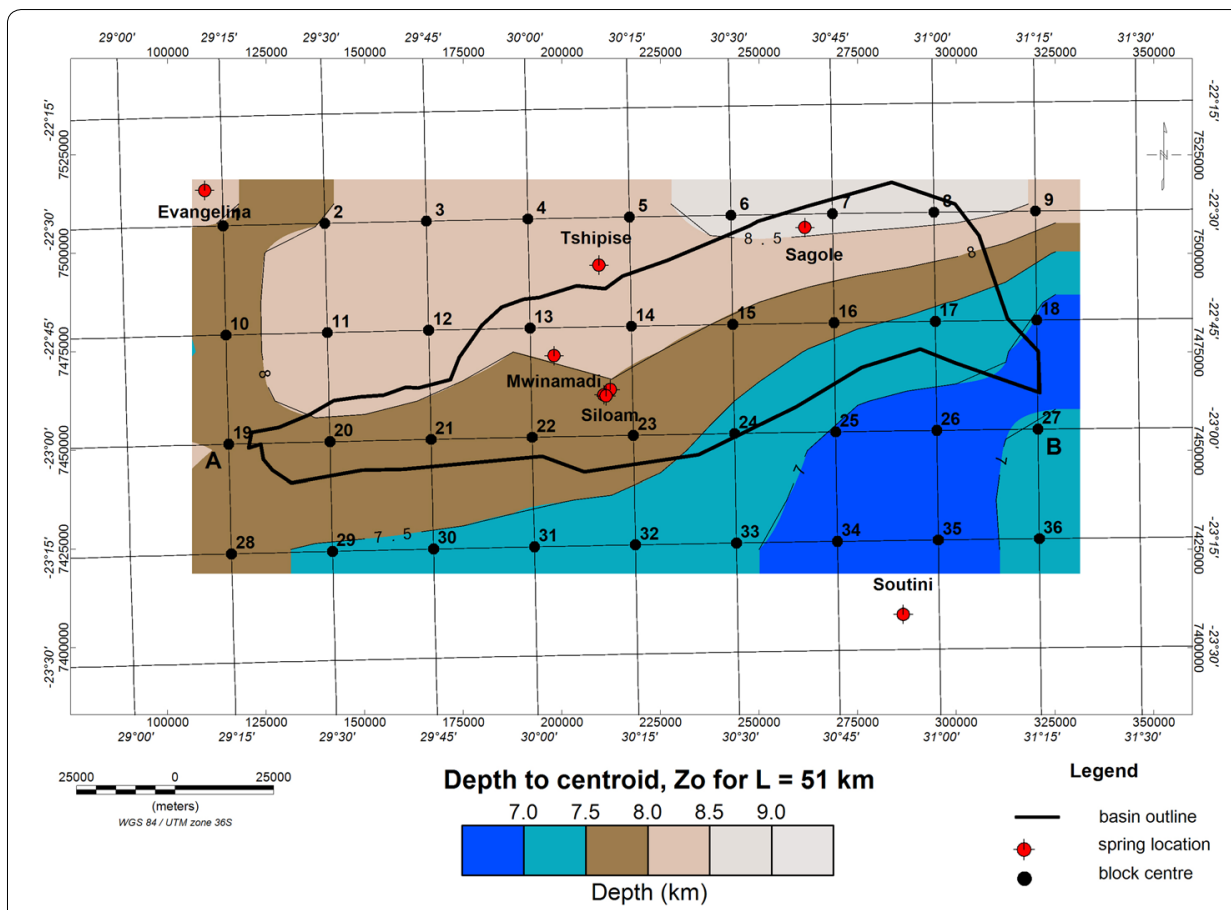

Fig. 16 Depth to the centroid $Z_{0}$ for 51 by $51-\mathrm{km}$ blocks, showing contours oriented southwest to northeast within the Basin

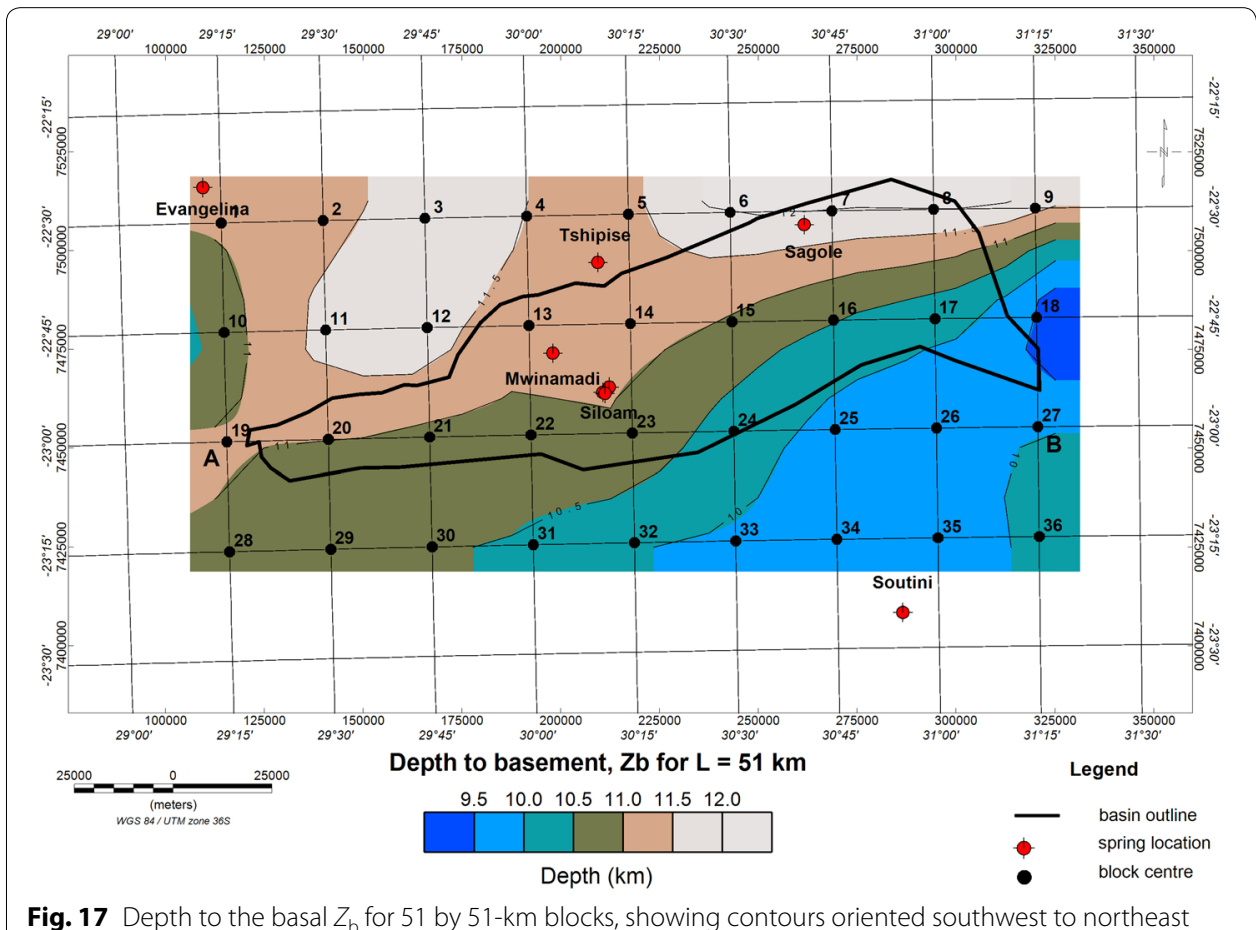




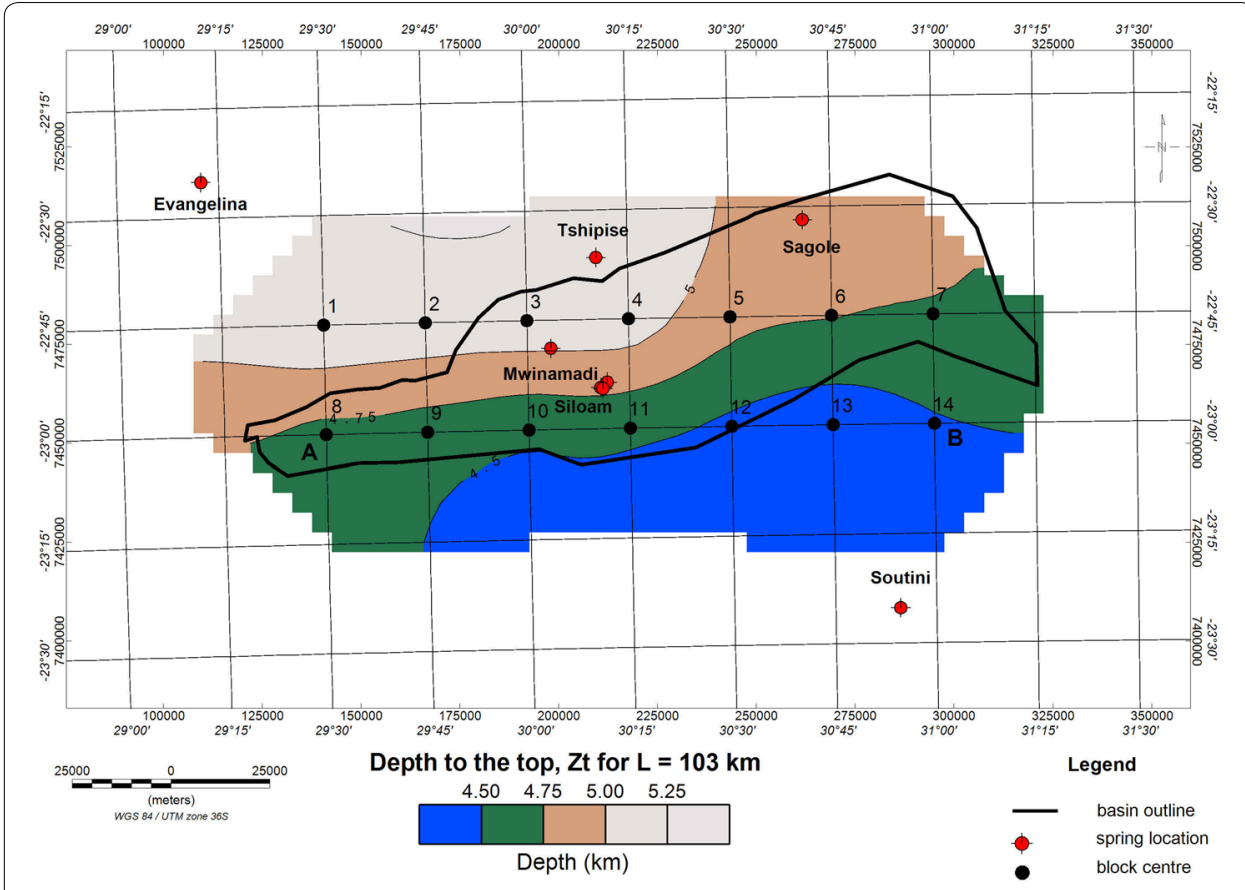

Fig. 18 Depth to the top $Z_{t}$ for 103 by 103-km blocks, showing contours oriented southwest to northeast within the Basin

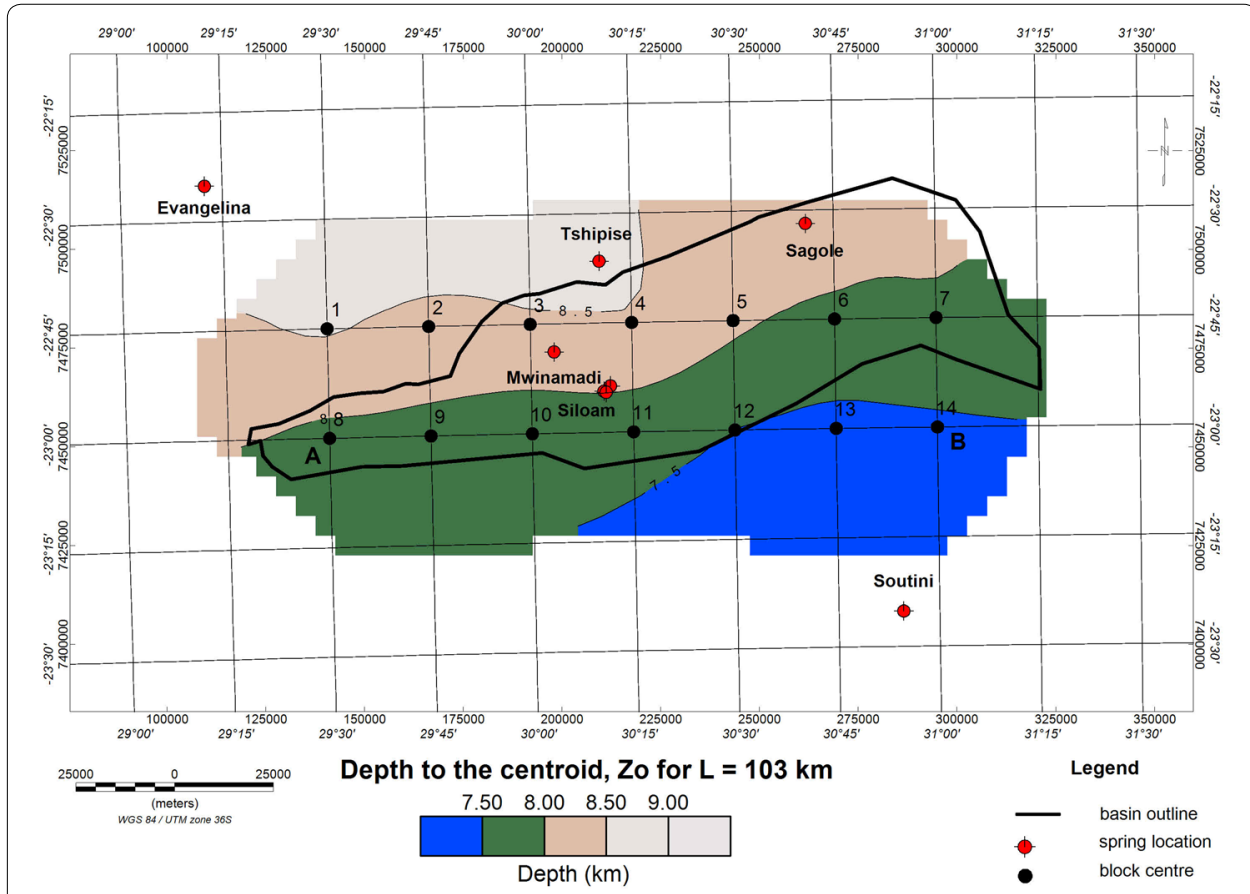

Fig. 19 Depth to the centroid $Z_{0}$ for 103 by $103-k m$ blocks, showing contours oriented southwest to northeast within the Basin 


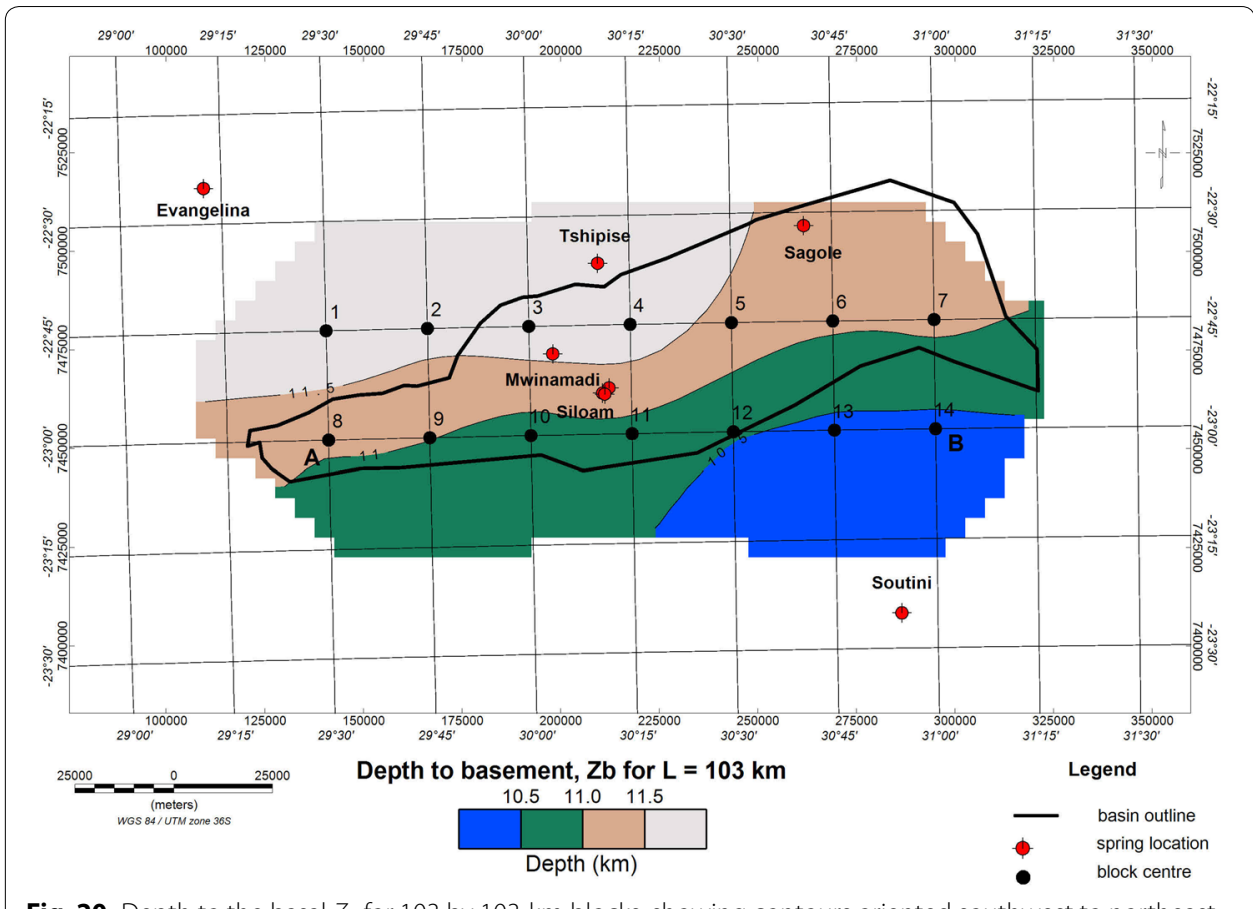

Fig. 20 Depth to the basal $Z_{\mathrm{b}}$ for 103 by $103-\mathrm{km}$ blocks, showing contours oriented southwest to northeast

The depth contours for blocks with a dimension $L$ of $103 \mathrm{~km}$ were generally oriented southwest to northeast with hot springs in the central part of the basin occurring within a zone with $Z_{\mathrm{t}}, Z_{\mathrm{o}}$, and $Z_{\mathrm{b}}$ depth ranges of $4.75-5.00 \mathrm{~km}$ (Fig. 18), 8.0-8.5 km (Fig. 19), and $11.0-11.5 \mathrm{~km}$ (Fig. 20), respectively.

The two independent method results defined the anticline at depths of $3.5-4.5 \mathrm{~km}$ in the central part of the basin.

The computed depths are comparable to the lithological thickness of 7-km-thick volcano-sedimentary material that was mentioned by Khoza et al. (2013). The research has shown that airborne magnetic data sets with larger window sizes are preferred for depth computations, as they preserve spectral signatures of deeper sources and reduce the contribution of shallower sources.

\section{Conclusions}

The magnetic source depths and heat source depths were determined for the Soutpansberg Basin from filtering and analysis of airborne magnetic data. The magnetic sources at depths of approximately $\pm 2 \mathrm{~km}$ can be attributed to shallow volcanic dykes and sills. The relatively shallower anticlinal feature in the central part of the Soutpansberg Basin at depths of $2-3.5 \mathrm{~km}$ is a prime target for geothermal investigation The deeper magnetic sources at depths below $4.8 \mathrm{~km}$ are present. The relatively shallow CPD at the $11.1 \mathrm{~km}$ within the basin outline makes the study area a potential target for geothermal investigations. The size of the magnetic data windows with dimensions of 51 by $51 \mathrm{~km}, 103$ by $103 \mathrm{~km}$, and 129 by $129 \mathrm{~km}$ that were used for the power spectrum analysis did not have a significant effect on the computed depths. Finally, the existence of a 


\title{
Soutpansberg Basin Geothermal Field was inferred from the existence of the hot springs, the 2-3.5-km-deep anticlinal feature, the approximate 3.5-12-km-volcano-sedimentary pile, magnetic source depths, and the computed depths to the basement.
}

\begin{abstract}
Abbreviations
CPD: Curie point depth; GMRDC: Govan Mbeki Research and Development Centre; IGRF: International Geomagnetic Reference Field; NRF: National Research Foundation; RAPS: Radially averaged power spectrum; RTP: Reduction to pole; SI: Structural index; WRC: Water Research Commission.

\section{Authors' contributions}

PN processed all the spectral analysis of the geophysical data and was responsible for literature searches. As this research was key for the scientific progression of PN, he was therefore the main editor of the manuscript. PN, the first author reviewed literature and generated images for the manuscript. The second author, OG offered supervision for the research and guidance with the interpretation of results. The role of OG was that of a postgraduate supervisor, offering scientific guidance and mentorship. OG reviewed the progress of the research. The availability of data processing software was supported by OG. All authors read and approved the final manuscript.
\end{abstract}

\section{Acknowledgements}

This research project was made possible by funding from the Water Research Commission (WRC) Project K1959/1/2010, the National Research Foundation (NRF) Grant UID 82443, and the Council for Geoscience Projects ST-2009-1015, ST-2011-1120, and ST-2013-1169. The Council for Geoscience is thanked for providing the regional airborne magnetic data and data processing resources. The assistance of the Govan Mbeki Research and Development Centre (GMRDC) at the University of Fort Hare is appreciated. Geosoft Inc. is thanked for providing data processing, imaging, and interpretation software. We are grateful for the informative discussions on geology and geothermal research that we had with Günther Brandl, Taufeeq Dhansay, and Peter Vivian-Neal. The Mining Qualifications Authority of South Africa (MQA) is thanked for funding students Mpumelelo Dube and Phathu Maligana, who assisted with some of the literature research as part of their internship. Support for the research on the development of geothermal resources by the communities in the Siloam and Sagole areas is appreciated.

\section{Competing interests}

Both the first and second authors are affiliated with the University of Fort Hare. The publication of research in esteemed journals is recorded by the University and the Department of Higher Education and Technology of the Republic of South Africa. The core interest of the authors is the promotion of scientific research. Successful publication has a bearing on one's rating and professional development. Results of the research would benefit agencies that seek to investigate the potential for geothermal development. The authors declare that they have no competing interests.

Received: 18 February 2016 Accepted: 10 June 2016

Published online: 23 June 2016

\section{References}

Abraham EM, Lawal KM, Ekwe AC, Alile O, Murana KA. Lawal AA (2014) Spectral analysis of aeromagnetic data for geothermal energy investigation of Ikogosi Warm Spring-Ekiti State, southwestern Nigeria. Geotherm Energy. 2014;2(1):1. doi:10.1186/s40517-014-0018-9.

Banks D, Schäffler J. The potential contribution of renewable energy in South Africa. Draft Update Report. 2006. p. 116. Bansal AR, Anand SP. Estimation of depth to the bottom of magnetic sources (DBMS) using modified centroid method from Aeromagnetic data of Central India. In: 9th Biennial International Conference and Exposition on Petroleum Geophysics. Hyderabad; 2013. p. 343.

Barker OB, Brandl G, Callaghan CC, Eriksson PG, van Der Neut M. The Soutpansberg and Waterberg groups and the Blouberg formation. In: Johnson MR, Anhaeusser MR, Thomas CR (eds). The geology of South Africa; 2006. p.301-18.

Bektas Ö, Ravat D, Büyüksaraç A, Bilim F, Ateş A. Regional geothermal characterisation of East Anatolia from aeromagnetic, heat flow and gravity data. Pure Appl Geophys. 2007;164:976-86. doi:10.1007/s00024-007-0196-5.

Bouligand C, Glen JMG, Blakely RJ. Mapping Curie temperature depth in the western United States with a fractal model for crustal magnetization. J Geophys Res. 2009;114:B11104. doi:10.1029/2009JB006494.

Bumby AJ, Eriksson PG, van der Merwe R, Maier WD. The stratigraphic relationship between the Waterberg and Soutpansberg Groups in Northern Province, South Africa: evidence from the Blouberg area. S Afr J Geol. 2001;104:205-16. doi:10.2113/1040205.

Cooper GRJ. A solution-space approach to the Euler deconvolution of map data. In: 11 th SAGA Biennial Technical Meeting and Exhibition; 2009.

De Beer JH, Stettler EH. The deep structure of the Limpopo Belt from geophysical studies. Precambr Res. 1992;55:173-86.

Dewangan P, Ramprasad T, Ramana MV, Desa M, Shailaja B. Automatic interpretation of magnetic data using Euler deconvolution with nonlinear background. Pure appl Geophys. 2007;164:2359-72.

Dolmaz MN, Ustaömer T, Hisarli ZM, Orbay N. Curie point depth variations to infer thermal structure of the crust at the African-Eurasian convergence zone, SW Turkey. Earth Planets Space. 2005:57(5):373-83.

Durheim RJ, Barker WH, Green RWE. Seismic studies in the Limpopo Belt. Precambr Res. 1992;55:187-200.

El Dawi MG, Tianyou L, Hui S, Dapeng L. Depth estimation of 2-D magnetic anomalous sources by using Euler deconvolution method. Am J Appl Sci. 2004;1(3):209-14. 
Eletta BE, Udensi EE. Investigation of the investigation of the Curie Point Isotherm from the magnetic fields of Eastern Sector of Central Nigeria. Geosciences. 2012;2(4):101-6. doi:10.5923/j.geo.20120204.05.

Guimarães SN, Ravat D, Hamza VM. Curie depths using combined analysis of centroid and matched filtering methods in inferring thermomagnetic characteristics of Central Brazil. In: Thirteenth International Congress of the Brazilian Geophysical Society; 2013.

Gwavava O, Ranganai RT. The geology and structure of the Masvingo greenstone belt and adjacent granite plutons from geophysical data, Zimbabwe craton. S Afr J Geol. 2009;112(3-4):277-90. doi:10.2113/gssajg.112.3-4.277.

Hsieh HH, Chen CH, Lin PY, Yen HY. Curie point depth from spectral analysis of magnetic data in Taiwan. J Asian Earth Sci. 2014;15(90):26-33.

Khoza D, Jones AG, Muller MR, Evans RL, Webb SJ, Miensopus M, Team SAMTEX. Tectonic model of the Limpopo belt. Precambr Res. 2013:226:143-56.

Komolafe AA. Investigation into the tectonic lineaments and thermal structure of Lake Magadi, Southern Kenya rift using integrated geophysical methods. MSc. Thesis, International Institute for Geo-Information Science and Earth Observation; 2010. p. 16-9.

Ledwaba L, Dingoko O, Cole P, Havenga M. Compilation of survey specifications for all the old regional airborne geophysical surveys conducted over South Africa. Council for Geoscience Report; 2009. p. 40.

Lin JY, Sibuet JC, Hsu SK. Distribution of the East China Sea continental shelf basins and depths of magnetic sources. Earth Planets Space. 2005;57(11):1063-72.

Maus S, Dimri V. Depth estimation from the scaling power spectrum of potential fields? Geophys I Int. 1996;124:113-20.

Mushayandebvu MF, van Driel P, Reid AB, Fairhead JD. Magnetic source parameters of two-dimensional structures using extended Euler deconvolution. Geophysics. 2001;66:814-23.

Nwankwo LI, Olasehinde PI, Akoshile CO. An attempt to estimate the Curie-point isotherm depths in the Nupe Basin, West Central Nigeria. Glob J Pure Appl Sci. 2009;15:427-33.

Nwankwo LI. Discussion on Spectral analysis of aeromagnetic data for geothermal energy investigation of Ikogosi Warm Spring —Ekiti State, southwestern Nigeria. Geotherm Energy. 2014;2014(2):11. doi:10.1186/s40517-014-0011-3.

Oasis Geosoft Montaj. Calculating the energy spectrum in MAGMAP, Montaj filtering how-to guide. Geosoft Inc;; 2014. p. 6

Okubo Y, Matsunaga T. Curie point depth in northeast Japan and its correlation with regional thermal structure and seismicity. J Geophys Res. 1994;99(B11):22363-71. doi:10.1029/94JB01336.

Pilkington M, Miles WF, Ross GM, Roest WR. Potential-field signatures of buried Precambrian basement in the Western Canada Sedimentary Basin. Can J Earth Sci. 2000;37(11):1453-71.

Pilkington M, Todoeshuck JP. Fractal magnetization of continental crust. Geophys Res Lett. 1993;20(7):627-30

Ravat D, Pignatelli A, Nicolosi I, Chiappini M. A study of spectral methods of estimating the depth to the bottom of magnetic sources from near-surface magnetic anomaly data. Geophys J Int. 2007;169(2):421-34. doi:10.1111/j.1365-246X.2007.03305.X.

Reid AB, Allsop JM, Granser H, Millett AT, Somerton IW. Magnetic interpretation in three dimensions using Euler deconvolution. Geophysics. 1990;55(1):80-91. doi:10.1190/1.1442774.

Reynolds JM. An introduction to applied and environmental geophysics. Wiley; 2011.

Salem A, Ushijima K, Elsirafi A, Mizunaga H. Spectral analysis of aeromagnetic data for geothermal reconnaissance of Quseir area, northern Red Sea, Egypt. In Proc. of the World Geothermal Congress; 2000. p. 1669-74.

Shabalala A, Nyabeze PK, Mankayi Z, Olivier J. An analysis of the groundwater chemistry of hot springs in the Soutpansberg basin in South Africa: recent data. S Afr J Geol. 2015;118(1):87-94. doi:10.2113/gssajg.118.1.87.

Schlömer T, Deussen O. Towards a standardized spectral analysis of point sets with applications in graphics. Konstanz: University of Konstanz; 2010. p. 1-2.

Spector A, Grant FS. Statistical models for interpreting aeromagnetic data. Geophysics. 1970;35:293-302.

Tanaka A. Magnetic and seismic constraints on the crustal thermal structure beneath the Kamchatka Peninsula. Volcanism and subduction: The Kamchatka Region; 2007. p. 91-6.

Tanaka A, Okubo Y, Matsubayashi O. Curie point depth based on spectrum analysis of the magnetic anomaly data in East and Southeast Asia. Tectonophysics. 1999;306(3):461-70.

\section{Submit your manuscript to a SpringerOpen ${ }^{\circ}$ journal and benefit from:}

- Convenient online submission

- Rigorous peer review

- Immediate publication on acceptance

- Open access: articles freely available online

- High visibility within the field

- Retaining the copyright to your article

Submit your next manuscript at $\boldsymbol{\nabla}$ springeropen.com 